\title{
The Making of 21st Century Doctors of Bhutan; Use of Artificial Intelligence, Big Data and Values Appropriate for the New Normal in the 21st Century
}

\section{Introduction}

Big Data and Artificial Intelligence (AI) is an integral part of "digital natives" or millennials including in our professional life. Many are handicapped without the presence of digital environment. The COVID-19 pandemic has forced both the economic and scientific world to resort to virtual meetings, virtual classes and even the WHO has gone virtual for many of its important meetings.
\end{abstract}

Tenzin, K. ${ }^{1}$, Karunathilake, I.M. ${ }^{2}$, Rimal, J. ${ }^{3}$, Wangdi, P. ${ }^{1}$, Gyamtsho, S. ${ }^{1}$, Tobgay, T. , Dorii, G. ${ }^{5}$, Pradhan, $D .^{6}$, Tshering, $D .^{6}$, Supe, $A .^{7}$, Jayasinghe, $S .^{2}$, Siebeck, ${ }^{8}{ }^{8}$ \& Tenzin, $T{ }^{1}$

However, humanistic values have served the medical practices well for centuries, therefore there is and need to explore on a convenient the marriage between time-tested values with new partners such as Al and Big Data.

\section{Artificial Intelligence and the Black Box Phenomenon}

The potential use of $\mathrm{Al}$ in Medical Education in Bhutan provides valuable insights. The positive aspect of technology includes reducing the work performed by humans, cost reduction, accuracy and fastness of diagnosis.

\footnotetext{
${ }^{1}$ Faculty of Postgraduate Medicine, Khesar Gyalpo University of Medical Sciences of Bhutan.

${ }^{2}$ Faculty of Medicine, University of Colombo, Sri Lanka. ${ }^{3} B P K I H S$, Dharan, Nepal.

${ }^{4}$ Institute of Health Partners, Thimphu, Bhutan.

${ }^{5}$ WHO- SEARO office, Delhi, India.

${ }^{6} \mathrm{CRRH}$, Gelephu, Bhutan.

${ }^{7}$ Former Dean and Director, KEM hospital, Mumbai, India.

${ }^{8}$ LMU, Munich, Germany.
}

Corresponding Author: Professor Indika Karunathillake Head, Department of Medical Education,

Head, WHO Collaborating Centre for Medical Education, Faculty of Medicine, University of Colombo, Sri Lanka.

Email: karunathilake@hotmail.com
However, there are risks to health professionals as well as IN service delivery of Al such as the "Black Box Phenomenon". Further, medical technologies are modifying in a rapid manner, which is not necessarily need of a doctor but more of economic driven (Supe, 2020; Siebeck, 2020).

One must be mindful about the Al ethics, moral, social and critical aspects. If a person is not well educated to handle $\mathrm{Al}$, there is a risk of cyberattack or receive misclassified medical information that will ultimately harm the lives of patients. Therefore, Al can never replace a selfreflective medical professional in human form. (Supe, 2020; Siebeck, 2020).

\section{Technological Domain in Medical Education}

The entire medical community must appreciate that the New Normal has accelerated the digital transformation of medical education. Simulation-based education and virtual reality has now become integral components of medical education. Many competencies such as clinical skills, procedure-based skills, team work, and leadership can be trained through simulation. With creativity and imagination, only sky is the limit". In the era of technology, make the best use of the technology and take the new normal as a blessing in disguise. If you look in the right places, tomorrow's technology is already there. (Karunatilaka, 2020; Siebeck, 2020; Pradhan, 2020)

\section{A Black Swan Event (COVID-19 Pandemic)}

COVID 19 pandemic has impacted the medical education globally. This black swan event has forced to reshape the future of medical education in a drastic manner. All stakeholders of medical education have been made to strategize on how to deliver the Teachinglearning activities at the times of black swan.

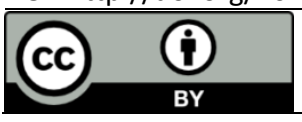

6

(C) SEAJME. This is an Open Access article distributed under the terms of the Creative Commons Attribution License (http://creativecommons.org/licenses/by/4.0/), which permits unrestricted use, distribution, and reproduction in any medium, provided the original author and source are credited 
The academic leadership must be flexible on adapting academic strategies for teachers to upgrade themselves on educational technologies. At the same time, the system must respect students by being flexible, engaging and encouraging active learning and connecting to the world beyond academics to get the bigger picture of health care needs (Rimal, 2020; Siebeck, 2020).

\section{Roles of Medical Education in Community's Well-being}

Bhutan has proud association of being only nation that uses Gross National Happiness instead of Gross Nation Product as a yardstick for growth and development. Bhutan has over 50 Hospitals including 10 bedded hospitals manned by 411 Medical Doctors and 1300 Nurses and paramedics. (Annual Health Bulletin, 2019). Free health care at all level of care, good leaders and strong PHC have been the strength of current Bhutan's health care system. As Bhutan's moves forward, there should be greater emphasis on the use of data in decision making. This can be achieved through medical education that focuses on use of data, research and cultural values that is unique to Bhutan (Tobgay, 2020).

A district doctor's roles are zeroed as (i) explicit roles and (ii) implicit roles. The explicit roles are those that are well defined and commonly known to the general public and others. The implicit roles remain ambiguous within the current context due to lack of clarity in operational mechanisms. Laying a simple $2 \times 2$ table of the role definition (explicit and implicit) and perception of the roles by a doctor (perceived or not perceived), four possible scenarios emerge (Dorji, 2020).

1. Roles are explicit and perceived by a doctor (Clinical care in a district hospital, emergency response and outbreak control).

2. Roles are implicit but perceived by a doctor (Technical support to specific areas such as serving as a training resource on specific diseases such as TB, HIV. Malaria, etc;).

3. Roles are explicit but not perceived (maintaining clinical standards and performance of hospitals).

4. Roles are implicit and not perceived by a doctor (Health services planning and strategic inputs, Stewardship for clinical governance in hospital and BHU clinical services, clinical mentoring and supportive supervision of BHU staff).
An analogy that, like a pilot in the cockpit who takes off the flight with accuracy and clear milestones, with the support of the whole crew and ground staff. A district doctor should be a visionary, systems thinker, team player, team lead in addition being an empathetic clinician. Those attributes combined with tools such as artificial intelligence and deep learning, and doctor's innate emotional and human intelligence (Dorji, 2020) is what a doctor of 21 st century should be.

\section{Teacher's Role in Medical Education}

The 21st century medical education is an era of 'dataism', meaning too much information. Both teacher and learners must develop an insight "How to navigate through the information to reach the diagnosis" (Gyamtsho, 2020; Pradhan, 2020; Wangdi 2020). In other words, make learner to "learn to become lifelong learners". The new outlook is required where technology is utilized as adjunct in patient care rather than as distraction or a barrier in learning. Technology is not the goal; it is the enabler. (Pradhan, 2020; Karunatilaka, 2020).

Classical examples of technology in day to day clinical teaching such as laparoscopic surgery, I-Cardiotocography, various learning apps and software (Gyamtsho, 2020). Use of these technological advancements has following advantages;

1. Trainees acquire better skills as it is convenient to use

2. Can share and discuss with colleagues better

3. Reduces the work load or pressure on staff

At the same time, a teacher must be aware of challenges faced by medical education today; Maintaining the balance between service delivery and the increasing demand of the society especially with the increase in the number of "digital natives" (Tshering, 2020).

\section{A Learner's Mind}

A trainee doctor today is encountered with multiple challenges, there is still much emphasis on the acquisition of knowledge. In 21 st century, an era of abundance of information and easy access would enable learners to change and redirect their energies to navigating (scavenging) to secure the correct information (Siebeck, 2020; Wangdi, 2020; Pradhan, 2020). 
Medical community must foresee in our clinical practice in context of;

- 21st Century patients knowing more about their health care needs. Are we prepared?

- Humanistic aspect of medicine as a core value. An urgent need!!!

- A happy marriage between technology and humanistic values.

- Healthcare that goes beyond merely treating symptoms but includes an art of caring for the whole "human being".

The Key messages that were generated from this first ever virtual conference at KGUMSB:

1. Bhutan needs doctors who believe in rich Bhutanese culture and $\mathrm{GNH}$ values with additional knowledge of Al.

2. Bhutan should consider establishing a medical college that nurtures Bhutanese culture and values which sustains the delivery of quality health services and ensures that the kingdom is self-reliant.

3. Bhutan must preserve its core values in medical education by incorporate $\mathrm{GNH}$ values in curriculum as mandatory subject in all its courses.

4. Urgent need to focus on implicit roles of district doctors as strategic thinker and planning to improve the health outcome of a population/community.

5. Investment in technology and necessary marriage between $\mathrm{Al}$, big data and Humanistic values as commanded by His Majesty at many of his Royal Addresses over the years.

\section{Acknowledgement}

The authors would like to express deepest appreciation to management of the University for guidance. Additionally all 11 panelists are thanked for their expertise and commitment.

\section{References}

Beaglehole, R. \& Bonita, R. (2015) Development with values: lessons from Bhutan. The Lancet, 385, 9971, pp. 848-849.

Khesar, K. (2008) Coronation Address of His Majesty King Khesar. The 5th Druk Gyalpo of Bhutan 7th November.

Dorji, G. (2020) Attributes of district doctors and values for Community's health "The making of 21st Century doctors of Bhutan; Use of Artificial Intelligence, big data and the values that fits the needs of 21 st Century ". (link: https://www.facebook.com/kgumsb/videos/3064 321253665544).

Gyamtsho, S. (2020) How to contextualize and incorporate the technological advancement in our day to day clinical teaching, A teacher's perspective" The making of 21st Century doctors of Bhutan; Use of Artificial Intelligence, big data and the values that fits the needs of 21st Century ". $\quad$ (link: https://www.facebook.com/kgumsb/videos/3064 321253665544).

Humanity and Technology; Interview with Gerd Leonhard. The Druk Journal http://drukjournal.bt/humanity-and-technology/

ICT Education in Bhutan's Tertiary Institution. The Druk Journal http://drukjournal.bt/ict-educationin-bhutans-tertiary-institutio

Jayasignhe, S. (2020) Role of values in Medical Education in 21st Century Bhutan " The making of 21st Century doctors of Bhutan; Use of Artificial Intelligence, big data and the values that fits the needs 21stCentury".(link:https://www.facebook.com/kg umsb/videos/3064321253665544)

Karunathilake, I.M. (2017) Technology Enhanced Learning with Limited Resources - Transforming Limitations into Advantages, South-East Asian Journal of Medical Education, 11, 1, pp. 1-2.

Karunatilake, I. M. (2020), Role of simulation and virtual reality in Medical Education of New Normal era, Virtual Health Professional's Education Conference " The making of 21 st Century doctors of Bhutan; Use of Artificial Intelligence, big data and the values that fits the needs of 21 st Century ". $\quad$ (link: https://www.facebook.com/kgumsb/videos/3064 321253665544)

Mahajan, R., Gupta, K., Gupta, P., Kukreja S., \& Singh, T. (2020) Multimedia instructional design principles: Moving from theoretical rationale to practical applications, Indian Paediatrics 57; June, 555-561.

Rimal, J. (2020) Future of Medical education in Region and Bhutan " The making of 21st Century doctors of Bhutan; Use of Artificial Intelligence, big data and the values that fits the needs of $21 \mathrm{st}$ Century ". (link: https://www.facebook.com/kgumsb/videos/3064 321253665544)

Supe, A. (2020) Big data, Ai and machine learning in HPE "The making of 21st Century doctors of Bhutan; Use of Artificial Intelligence, big data and the values that fits the needs of 21 st Century ". (link:

https://www.facebook.com/kgumsb/videos/3064 321253665544) 
Supe, A. (2020) Health Professions education and Corona times, NJIRM 2020;1(2) Mar-Apl, 0-2.

Siebeck, M. (2020) Technical domain" an emerging domain in $T-L$, besides the traditional Cognitive(knowledge), Psychomotor(skill) and affective(attitude) domains, "The making of 21st Century doctors of Bhutan; Use of Artificial Intelligence, big data and the values that fits the needsof21stCentury".(link

https://www.facebook.com/kgumsb/videos/3064 321253665544)

Tobgay, T. (2020) Critical analysis of Bhutan Health systems "The making of 21 st Century doctors of Bhutan; Use of Artificial Intelligence, big data and the values that fits the needs of 21 st Century ". (link:

https://www.facebook.com/kgumsb/videos/3064 321253665544)
Tshering, D. (2020) Role of technology in Medical education,"The making of 21st Century doctors of Bhutan; Use of Artificial Intelligence, big data and the values that fits the needs of 21 st Century ". (link:

https://www.facebook.com/kgumsb/videos/3064 321253665544)

Wangdi, P. (2020) Making of 21st Century Physicians',"The making of 21st Century doctors of Bhutan; Use of Artificial Intelligence, big data and the values that fits the needs of 21st Century ". (link: https://www.facebook.com/kgumsb/videos/306 4321253665544) 